\title{
Conditioning in garter snakes: Aversion to palatable prey induced by delayed illness*
}

\author{
GORDON M. BURGHARDT \\ University of Tennessee, Knoxville, Tennessee 37916 \\ and \\ HARDY C. WILCOXON and JAMES A. CZAPLICKI \\ Peabody College for Teachers, Nashville, Tennessee 37203
}

\begin{abstract}
Garter snakes (Thomnophis sirtalis) accustomed to a fish diet were injected with either saline or lithium chloride $30 \mathrm{~min}$ following the ingestion of earthworms. On subsequent tests at 4-day intervals, the $\mathrm{LiCl}$-injected snakes showed significantly increased attack latencies to worms, which were often refused, but not to fish. Behavioral observation of feeding and concurrent tests with surface substance extracts of worm and fish indicate that chemosensory mediation is involved.
\end{abstract}

It has long been known that rats are capable of learning to avoid poisoned food, provided their first encounter with it is not lethal (Bamett, 1963). Careful laboratory investigations of kindred phenomena have shown that such adaptive avoidance learning can occur in the rat even though an interval of many minutes, or even hours, elapses between exposure to virtually any distinctive taste and the subsequent onset of an arbitrarily induced illness (e.g., Garcia, McGowan, Ervin, \& Koelling, 1968; Rozin, 1969). A similar effect has been reported in bobwhite quail (Wilcoxon, Dragoin, \& $\mathrm{Kral}, 1971)$. Moreover, these birds, unlike rats, can also learn avoidance on the basis of a purely visual cue when the consequence of ingestion is a delayed illness (toxicosis). In a more naturalistic context, Brower (1969) postulates a similar process by which bluejays learn to avoid toxic Monarch butterflies on sight. More comparative studies are needed on this phenomenon and its sensory control.

Snakes have received little attention in traditional learning studies and with largely equivocal results (Crawford \& Bartlett, 1966; Crawford \& Holmes, 1966; Kellogg \& Pomeroy, 1936; Kleinginna, 1970; Wolfe \& Brown, 1940). In this report the modification of feeding preference in adult garter snakes (Thamnophis sirtalis) resulting from a single aversive conditioning trial is investigated. Ingestion of normally palatable earthworms (Lumbricus terrestris) was followed $30 \mathrm{~min}$ later by drug-induced toxicosis. Lithium chloride was used because it is generally considered the most effective chemical for inducing toxicosis in other species, particularly the rat (Boland, 1973).

\footnotetext{
*Supported by Grant HD00973 and NIMH Grant 15707 . We thank James Dwyer and Steve Handel for assistance. The experiment was performed at Peabody College while the senior author was in residence as a Visiting Scientist in the John F. Kennedy Center for Research in Education and Human Development.
}

Feeding responses and prey preferences in garter snakes can be elicited by distal chemical cues alone, most probably mediated by the Jacobson's organ-tongue system even in the absence of prior feeding experience (Burghardt, 1970). Such initial preferences can be modified easily in favor of chemical cues presented on cotton swabs from prey routinely fed (Fuchs \& Burghardt, 1971). In light of such findings, observations and measurements were made of the appetitive behavior elicited by extracts of chemical surface substances of prey objects using the methods developed in the above papers as well as of the appetitive and ingestive behavior elicited by the prey objects themselves.

\section{METHOD}

The Ss were four adult Thamnophis sirtalis captured in Florida approximately 6 weeks prior to the experiment. Their snout-vent lengths ranged from 56.2 to $61.4 \mathrm{~cm}$ and their weights from 79.8 to $93.7 \mathrm{~g}$. For 2 weeks prior to the experiment, they were housed individually and fed exclusively on Northern fathead minnows (Pimephales promelas). Although five snakes were available, the four used were those that underwent skin molting (ecdysis) within 3 days of the start of the experiment, eliminating for the intended duration of testing any possible effects due to the physiological, temperamental, or feeding changes snakes undergo during the few days before they shed their skins.

The experiment itself took place in a small air-conditioned windowless room maintained at $23^{\circ}-25^{\circ} \mathrm{C}$ and illuminated on a 12 -h light-dark cycle. The snakes were kept singly in $30-\mathrm{cm}$ wood cubical boxes with a hinged hardware cloth top and one clear plastic side oriented away from the $E$ under the edge of a small table. One hour before any testing or feeding, the houselights were turned off and two 15-W fluorescent fixtures behind the plastic sides under the table were turned on. This arrangement meant that all room illumination passed through the snake cages with minimal scatter, facilitated by the use of opaque plastic sheeting extending from the table down to the top of the plastic side of the cage. The light was bright in the cages, enhancing observation, but dim in the room, reducing disturbance to the snakes while allowing test preparation and data recording (see also Gove. 1971). Each cage floor was 


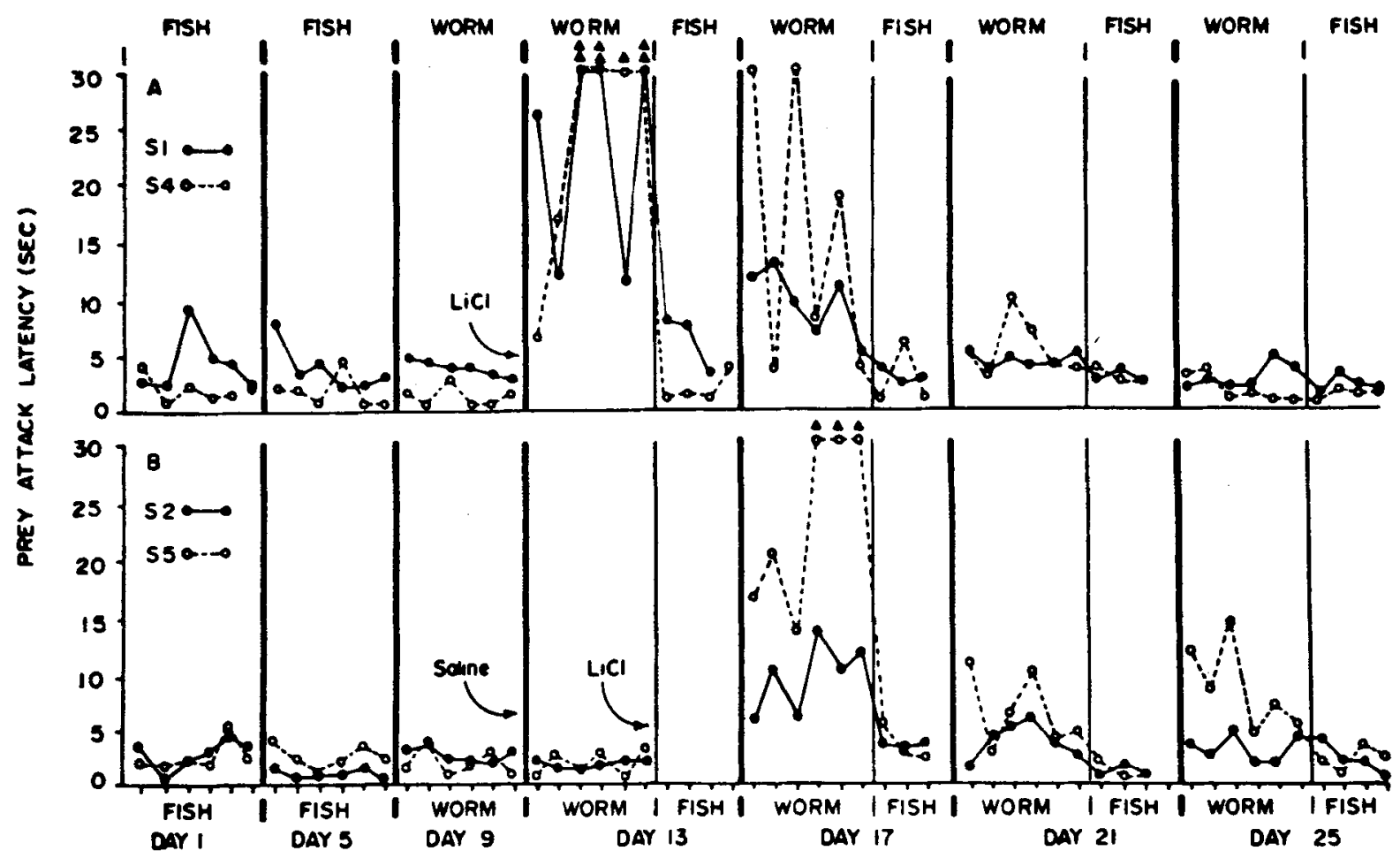

SUCCESSIVE PRESENTATIONS OF PREY

Fig. 1. Prey attack latency to ingestion in four garter snakes fed fish or worms every 4 days. Injections were 30 min after the final feeding on a given day. $\Delta$ indicates that the food was not taken within 30 sec.

covered with a Kimberly-Clark absorbent cage liner (changed 2 days prior to every feeding), a glass water bowl, and a piece of broken brick. Two persons observed all test sessions.

Chemical surface substance extracts were prepared from both minnow (F) and earthmore (W) the day before the experiment began and frozen in small glass vials until thawed to room temperature for use in testing. A $3-\mathrm{g} / 20$-cc-prey distilled water ratio was used at $60^{\circ} \mathrm{C}$. After gently stirring for $2 \mathrm{~min}$, the prey was removed and the extract centrifuged (modified from Burghardt, 1969).

Extract testing was performed by dipping a $15-\mathrm{cm}$ cotton swab into the extract, slowly introducing it into the animal's cage, and bringing it to within $1-2 \mathrm{~cm}$ of its snout, slightly to one side. Timing began at this moment. Attack latencies were recorded as well as tongue flicks directed toward and away from the swab. The swab was removed at the moment of attack. If no attack occurred within $60 \mathrm{sec}$, the swab was removed. During most sessions, coded extract vials were employed, although the clarity of the results often cued the Es to the identification of the extracts.

Feeding the prey was performed every 4 days in the same manner as extract testing, except that the food was held with a $30-\mathrm{cm}$ forceps, the maximum period was $30 \mathrm{sec}$, and the snake was allowed to grab and swallow the prey. If it dropped the food within the 30-sec period, it was picked up, offered again, and the final latency recorded. Fish and worm pieces averaged $1.3 \mathrm{~g}$ each (blotted weight). The minnows were frozen and thawed as needed. The worms were maintained live, but they were killed by brief scalding in hot water immediately before being cut into equivalently sized pieces.

On the first day of the experiment, the four snakes were tested alternately at S-min intervals on each prey extract three times. Two snakes (Nos. 1 and 2) began with $W$ extract and two $(4$ and 5 ) with the $F$ extract. Forty-five minutes following the last extract test, each snake was offered six fish at 5-min intervals. As can be seen in Fig. I, all snakes readily ate all the fish with few latencies longer than $5 \mathrm{sec}$. Four days later the entire procedure was replicated, except that the extract testing order was reversed (such balancing took place throughout the experiment). Again it can be seen that all the fish were readily eaten. From this point on, the snakes were also tested on the prey extracts the day before being fed. Based on the extract results through Day 9 , the snakes were divided into two groups: A, Nos. 1 and $4 ; B$, Nos. 2 and 5. The two snakes most responsive to $\mathrm{W}$ were placed in the former group.

On Day 9 all snakes were offered six pieces of worm instead of fish and, as can be seen in Fig. 1, this new food was taken as quickly as the fish had been taken in previous feeding sessions. After $30 \mathrm{~min}$ the Group A Ss (1 and 4) were injected with a .45-molar solution of $\mathrm{LiCl}$ (lithium chloride). A 25-ga needle was gently slid under a ventral scale halfway between the snout and the vent and $3 \mathrm{cc}$ per $100 \mathrm{~g}$ of body weight was injected. The control animals ( 2 and 5$)$ were identically injected with physiological saline in the same liquid to body weight ratio.

On Day 13, after the extract tests, all four snakes were tested with worms in the same manner as on Day 9. However, in Group A, $30 \mathrm{~min}$ after the last worm piece was offered, each snake was offered fish at 5 -min intervals until it had eaten a total (worm plus fish) of six pieces of food. Thirty minutes after their last piece of worm, the saline snakes (B) were injected with the $\mathrm{LiCl}$ solution. Group A Ss were not injected but placed, in effect, on extinction. All the snakes were offered six pieces of worm followed by three fish for three more feedings at 4-day intervals (Days 17, 21, and 25). The three fish were offered to the snakes on Day 215 min rather than $30 \mathrm{~min}$ after the last worm piece to evaluate whether the 30 -min wait had anything to do with the short fish latencies.

\section{RESULTS}

As shown in Fig. 1A, the original $\mathrm{LiCl}-$ injected snakes refused the worm on 7 of the 12 presentations and took 
it at considerably longer latencies than previously when they did attack. However, the snakes ate the fish each time and the latency of these attacks was shorter in every instance than the S's worm latency. Moreover, there was no significant difference between the attack scores to fish on Day 13 as compared to Day 5. Thus, the reluctance to eat was specific to worms. The control snakes, on the other hand, showed no increased latency to worm after their injection with saline (Fig. 1B); in fact, $\mathrm{S} 2$ showed a small decrease.

On Day 17 the animals injected with saline (Fig. 1B) on Day 9 (Group A) still showed an aversion to worm when compared to the first worm presentation, although the magnitude of the effect was clearly diminishing. The two control Ss injected with $\mathrm{LiCl}$ on Day 13 evidenced, in both cases, a significant delay in their attack scores to worm as compared to their behavior toward worm prior to the conditioning trial. S 5 even refused the worm three times. The response of all Ss to fish was faster than to worm. Comparing the mean response latency to worm (nonattacks scored as $30 \mathrm{sec}$ ) before and after $\mathrm{LiCl}$ for all four snakes led to a highly significant dependent $t$ $(\mathrm{t}=5.16, \mathrm{df}=3, \mathrm{p}<.01)$.

Extinction proceeded apace on Day 21. The 5-min instead of $30-\mathrm{min}$ interval between worm and fish apparently had no effect. On Day 25 extinction was virtually complete. Group A Ss did not respond to worm slower than to fish or slower than they had responded to worm prior to treatment. In Group B the same held true for S 2. However, Snake 5 still evidenced both slower attack latencies to worm than had been the case on Day 13 and longer latencies to worm than to fish.

The results of the extract tests will be briefly discussed. A tongue flick-attack score was calculated for each extract presentation. This tongue flick-attack score has proven to be a useful method for combining attack latency and tongue-flick data, with a higher score characterizing a stronger extract or a more responsive snake (Burghardt, 1969).

In Group A high mean scores $(>100)$ were given to both extracts by each snake prior to injection with $\mathrm{LiCl}$, while low scores to both extracts were evidenced following injection $(\leqslant 3.0)$. However, as extinction proceeded, the responsivity to fish extract increased prior to and differentially from the responsivity to worm extract. This differential recovery during the extract tests indicates a chemical discrimination, most likely mediated by Jacobson's organ (Burghardt, 1970). Group B snakes did not show the virtual abolishment of all response to both extracts the first post- $\mathrm{LiCl}$ testing. Nonetheless, the worm scores were reduced to $12.7 \%$ and $1.1 \%$ of the preinjection rate, while the fish scores were reduced to $37.4 \%$ and $24.3 \%$, respectively.

\section{DISCUSSION}

The data clearly show that a single injection of $\mathrm{LiCl}$ $30 \mathrm{~min}$ after feeding on worms can induce an aversion to them relative both to prior responses to that prey and to a different type of prey presented at the same feeding.
The latter evidence is critical in demonstrating that a nonspecific general aversion to all food items was not created. The extract results suggest that in the snake illness-induced prey aversions can be mediated by a chemical cue via Jacobson's organ. Further, the swab response may be a more sensitive general indicator of a prior illness than is response to food itself. However, it will be noted in Fig. 1 that after the illness all animals ate one or more worms before they began to reject them. If information of the type presented by extracts on cotton swabs totally mediated the aversion, then this result is inexplicable. Watching the animals clearly gave a clue about what is going on. The animal would seize the prey, admittedly at longer latencies than previously, and then take considerably longer to swallow it, often holding it between its jaws for $1.2 \mathrm{~min}$. Normally this size prey would be completely swallowed in less than $10 \mathrm{sec}$. On subsequent trials the snakes would often drop the worm as soon as they initially struck it and only take it the second or third time it was picked up with the forceps, if at all.

Gustation, then, is perhaps an important chemosensory mechanism involved in the association of a distinctive food with a subsequent arbitrarily induced illness. Perhaps the snakes needed to get the worm in their jaws to reactivate the association of food with illness. Then, they would secondarily associate the odcr with the taste and reject the prey without even, in some cases, a single tongue flick, let alone an attack. Those familiar with the voracious appetite of hungry garter snakes for earthworms will appreciate the "self-control" exhibited by these experimental Ss. This result is also in keeping with the finding that naive newborn snakes of this species will readily attack slugs when first encountered but will then avoid them after but a single experience with one in its mouth (Burghardt, 1969). In this case, however, ingestion was not necessary for subsequent avoidance without physical contact.

The demonstration of rapid one-trial conditioning in snakes over a long delay and with an unambiguous effect, illustrates both the potency of what seems to be a very adaptive process and its widespread occurrence in vertebrates. Indeed, this learning might be very valuable in snakes since potential prey are often poisonous (Licht \& Low, 1968).

\section{REFERENCES}

Bamett, S. The rat: $A$ study in behavior. London: Methuen, 1963.

Boland, F. J . Saccharin aversions induced by lithium chloride toxicosis in a backward conditioning paradigm. Animal Learning \& Behavior, 1973, 1, 3-4.

Brower, L. P. Ecological chemistry. Scientific American, 1969 , 220, 220-229.

Burghardt, G. M. Comparative prey-attack studies in newborn snakes of the genus Thamnophis. Behaviour, 1969, 33 $77-114$

Burghardt, G. M. Chemical perception in reptiles. In J. W. Johnston, Jr., D. G. Moulton, and A. Turk (Eds.), Communication by chemical signals. New York: Appleton-Century-Crofts, 1970. Pp. 241-308. 
Crawford, F. T., \& Bartlett, C. W. Runway behavior of the gray rat snake with food and water reinforcement. Psychonomic Science, 1966, 4, 99-100.

Crawford, F. T., \& Holmes, C. E. Escape conditioning in snakes employing vibratory stimulation. Psychonomic Science, 1966, 4, 125-126.

Fuchs, J. L., \& Burghardt, G. M. Effects of early feeding experience on the responses of garter snakes to food chemicals. Learning \& Motivation, 1971, 2, 271-279.

Garcia, J., McGowan, B. K., Ervin, F. R., \& Koelling, R. A. Cues: Their relative effectiveness as a function of the reinforcer. Science, 1968, 160, 794-795.

Gove, D. The responses of ecologically dissimilar populations of the water snake, Natrix sipedon sipedon, to surface extracts of prey species, with observations on feeding and defense behaviors. Unpublished MS thesis, University of Tennessee, Knoxville, 1971.

Kellogg, W. M., \& Pomeroy, W. B. Maze learning in water snakes Tropidonotus fasciatus var. sipedon. Journal of Comparative Psychology, 1936, 21, 275-295.
Kleinginna, P. R., Jr. Operant conditioning in the indigo snake. Psychonomic Science, 1970, 18, 53-55.

Licht, L. E., \& Low, B. Cardiac response of snakes after ingestion of toad paratoid venom. Copeia, 1968, 547-551.

Rozin, $\overline{\mathbf{P}}$. Central or peripheral mediation of learning with long CS-US intervals in the feeding system. Journal of Comparative \& Physiological Psychology, 1969, 67, 421-429.

Wilcoxon, H. C., Dragoin, W. B., \& Kral, P. A. Illness induced aversions in rat and quail: Relative salience of visual and gustatory cues. Science, 1971, 171, 826-828.

Wolfe, D. L., \& Brown, C. S. A learning experiment with snakes. Copeia, 1940, 134.

(Received for publication June 27, 1973; accepted August 10,1973.) 